\title{
AGRO-CLIMATIC CHARACTERIZATION OF TWO SELETED STATIONS IN THE SOUTHERN WEST BENGAL, INDIA
}

\author{
Saon Banerjee ${ }^{1}$, Asis Mukherj ${ }^{1}$, Apurba MukhopadhayaP ${ }^{2}$, B. SaikiaTP²PT, S. \\ Bandyaopadhaya $^{3}$ and Sudip ChatterjeeTP ${ }^{4} \mathrm{PT}$
}

\begin{abstract}
Maximum temperature, minimum temperature and rainfall data of Bankura (1992-2007) and Canning (1960-2006) were analyzed for assessing climatic trend and agro-climatic characterization of redlateritic and coastal Zones of West Bengal respectively. These two zones are the most vulnerable regions to climate change in West Bengal, hence selected for the present study. While average values of annual maximum temperature and annual minimum temperature were used for climatic trend analysis, no definite trend was observed. So, maximum temperature of the hottest month and minimum temperature of the coldest month were used for detecting climatic trend. The maximum temperature shows positive trend for both the stations. An increasing trend of annual rainfall was also observed. In case of agro-climatic characterization the agricultural draught, meteorological draught, seasonal rainfall and rainfall probability using Markov-chain model were analyzed for the said two stations. Kharif crops of Bankura encountered two years (2000 \& 2005) agricultural draught within 2000 -2007, whereas kharif crops of Canning encountered agricultural draught in 2006 within the said period. Likewise, the deviation of seasonal rainfall and probability of two consecutive wet weeks with different levels $(10,20,30,40,50$ and $60 \mathrm{~mm})$ of weekly total rainfall was worked out.
\end{abstract}

Keywords: climatic trend, agro-climatic characterization, Markov chain model, rainfall probability

\section{INTRODUCTION}

The elevated temperature and $\mathrm{CO}_{2}$ level by induced climate change are not only affecting the growth of the crop but also the cropping pattern of a region. High temperature enhancing evaporation may give rise to higher rainfall which may be different from that expected. Moreover, in recent past abnormalities in monsoon is also observed.

Several rainfall related risk analysis have been done for West Bengal with the help of incomplete gamma distribution as well as markov chain method which are done mostly in discrete places (Chakraborty and Chakraborty, 1991; Chakraborty et al., 1990). In case of rainfall probability analysis it is considered that the crop water requirement of Kharif rice is high as it is cultivated in standing water. It has been observed that $3.5 \mathrm{~mm}$ evapotranspiration per day and $3.5 \mathrm{~mm}$ percolation per day are optimum. So the water requirement per day is $7 \mathrm{~mm}$. So the weekly water requirement is $49 \mathrm{~mm}$ which is rounded to $50 \mathrm{~mm}$ weekly.

Based on this threshold value the rainfall probability analysis is the most common one (Thom, 1966). In the present paper, the agricultural, meteorological and seasonal drought was analysed along with rainfall probability and climatic trend.

1 AICRP on Agro-meteorology, Directorate of Research, B.C.K.V., Kalyani, India, PIN: 741235. West Bengal, India.

2 Network Project on Climate Change (Kalyani Centre), B.C.K.V., Kalyani.

3 Agrimet Section, Regional Meteorological Centre, IMD, Kolkata, India.

4 River Research Institute, West Bengal, India. 


\section{MATERIALS AND METHODS}

\section{Study area:}

The study was carried out taking the weather data of Bankura and Canning, representing the Redlateritic zone and the Coastal-saline zone of West Bengal. These two zones are the most vulnerable regions to climate change in West Bengal.

Agriculture accounts for almost $70 \%$ of the Bankura district's income whereas $80 \%$ of the farmers are small \& marginal. However due to protective irrigation system, land reforms and use of high fertile \& hybrid crops the district is now not so poor as it was. A vast area of bankura is not cultivable due to undulation of land and morum soil. About $46 \%$ of the net cropped area is under Irrigation. The gross cropped area is about 6 lakh ha. and cropping intensity is 147\%. Rice, Wheat, Oil seeds and Vegetables are the Principal Crop occupied major of the gross cropped area. Most of the Pre-Kharif and Kharif rice are grown in rainfed condition. H.Y.V. crops occupied about $9 \%$ in this district considering $100 \%$ in summer rice. Agriculture is largely dependent on the vagaries of monsoon. Drought constitutes a major hazard in the district. Intermittent gaps of in precipitation and moisture stress during the monsoon gives rise to serious set back in production during the Kharif, which is the main stay of Agriculture in the district (www.Bankura.com).

Mono-cropping is the main practices in the Coastal-saline zone and this zone needs special attention from the agricultural researchers. Research on multiple cropping, identification of elite genetic resources, particularly for rice, introduction of new crops needs the knowledge base of rainfall and run-off, soil moisture regime, residual moisture and some other basic data. Recent success of sunflower besides traditional vegetable chilli during winter after rice has drawn attention to improve the knowledge on crop-climate-soil relationship issues.

\section{Markov-chain model:}

The model is used here for the rainfall probability analysis for receiving 10, 20, 30, 40, 50 and $60 \mathrm{~mm}$ rainfall in the said two zones.

\section{RESULT AND DISCUSSION}

\section{Rainfall and temperature trend analysis:}

Maximum and minimum temperature data of Bankura station were analysed for detection of temperature change over years. No significant positive or negative trend was observed for the said station. However, in 1995 onwards, during monsoon months, both the maximum and minimum temperature was more (Fig. 1).

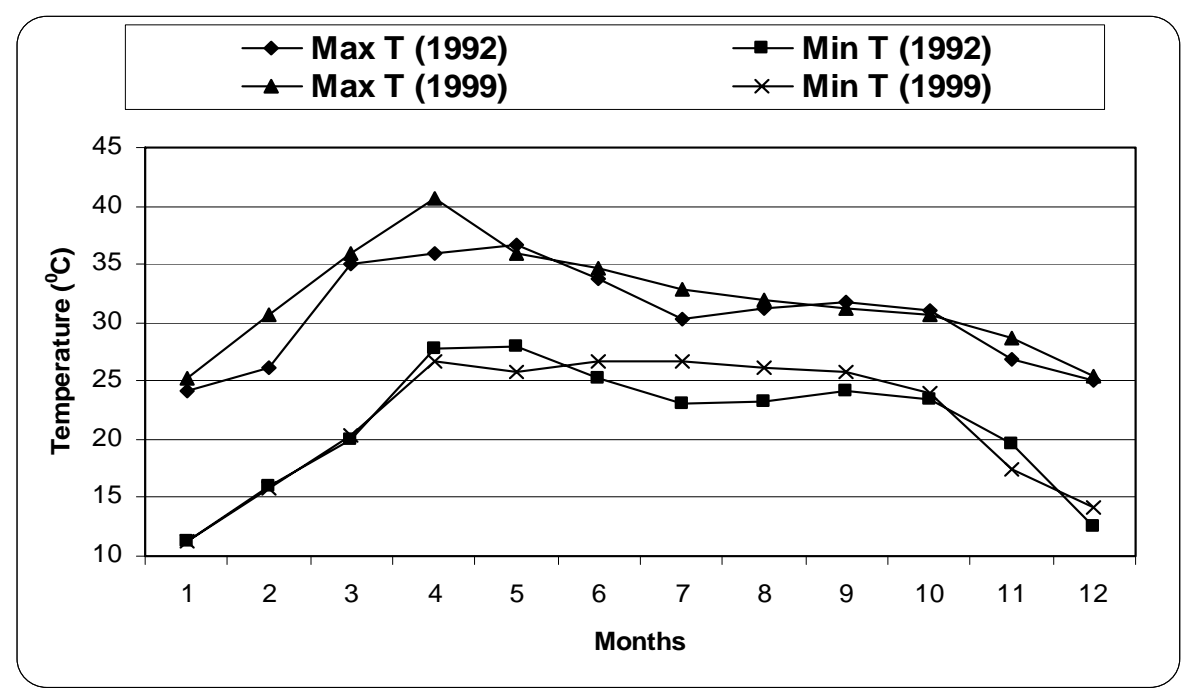

Fig. 1: Variation of monthly maximum and minimum 


\section{temperature of Bankura for two selected years}

The total annual rainfall of Canning station was collected from India Meteorological Department for the period 1959 to 2003. The annual average rainfall of this region is $2114 \mathrm{~mm}$ (Fig. 2). It was observed that the amount of rainfall increase gradually with progress of year. The increment was highly remarkable during 1975 to 1990 . During this period almost all year's rainfall amount was higher than the normal value. However after 1990 the rainfall amount decreased drastically and became at par with nineteen fifties database.

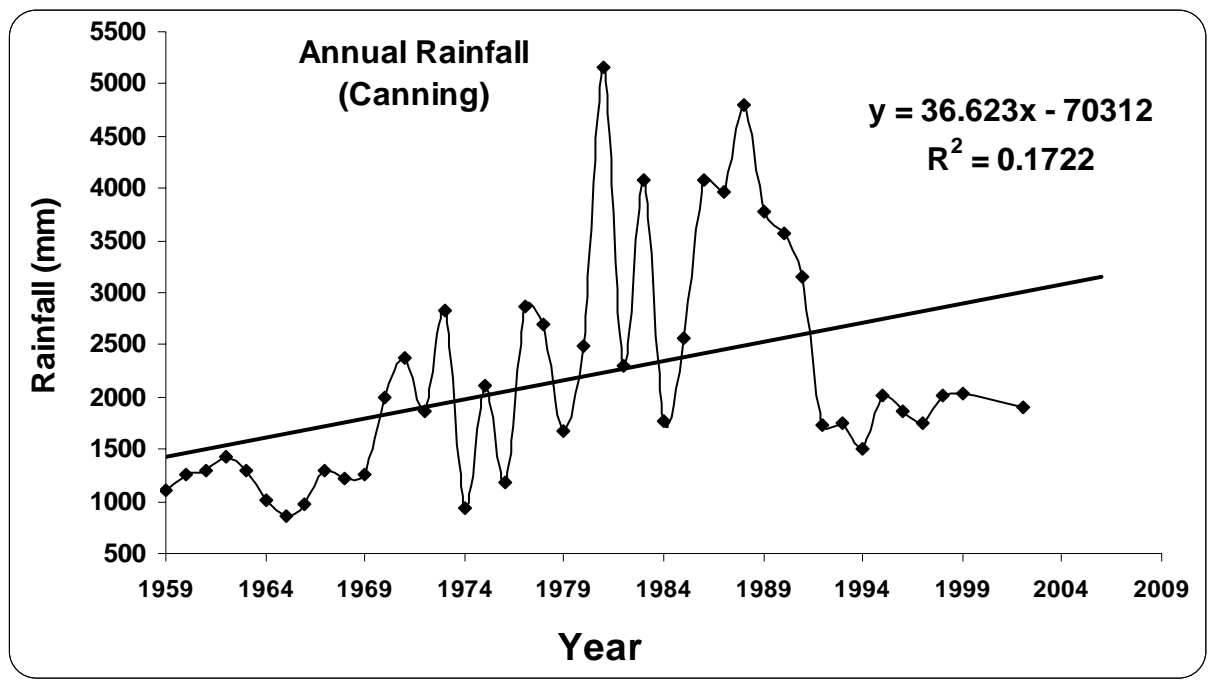

Fig. 2: Variation of annual rainfall in Canning station

\section{Agricultural drought analysis:}

Bankura station: Among eight years data, only two years (2000 \& 2005) crop encountered agricultural drought during Kharif season. In contrast to Kharif season, except 2003 all years under study showed Rabi season agricultural. drought. During 2000, two spell of consecutive four weeks drought period was noticed for both Kharif \& rabi season (Table 1).

Table 1: Kharif and rabi season agricultural drought for Bankura station

\begin{tabular}{|l|l|l|l|}
\hline Kharif & Week & Rabi \\
\hline Year & $24-27$ & Year & Week \\
\cline { 2 - 4 } & $39-42$ & \multirow{2}{*}{2000} & $40-45$ \\
\cline { 3 - 4 } & $38-41$ & & $46-51$ \\
\hline 2005 & & 2001 & $42-47$ \\
\hline & & 2002 & $47-52$ \\
\hline & & 2004 & $42-47$ \\
\hline & & 2005 & $44-49$ \\
\hline & & 2006 & $46-51$ \\
\hline & & 2007 & $47-52$ \\
\hline
\end{tabular}

Canning station: During Kharif season only two years $(1998,2006)$ showed agricultural drought. However, except 1998 all other years showed agricultural drought during Rabi season. The intensity of agricultural drought during Rabi season was higher during 2006 (Table 2).

\section{Meteorological drought analysis:}

Bankura: Except 2000, all years showed increased annual rainfall from average annual rainfall value. During 2000, the annual rainfall decreased by around $24 \%$ from the normal value and this caused a mild drought during this year (Table 3). 
Canning: Except1994, all years showed above rainfall from average yearly rainfall. During the year 1994, the annual rainfall decreased by around 13\% from the normal value and this caused a mild drought during this year (Table 4).

Table 2: Kharif and rabi season agricultural drought for Canning station

\begin{tabular}{|l|l|l|l|}
\hline Kharif & Week & Rabi & \\
\hline Year & $38-41$ & Year & Week \\
\hline 1998 & $39-42$ & 1992 & $43-48$ \\
\hline 2006 & & 1993 & $45-50$ \\
\hline & & 1994 & $47-52$ \\
\hline & & 1995 & $46-51$ \\
\hline & & 1996 & $46-51$ \\
\hline & & 1997 & $40-45$ \\
\hline & & 1999 & $44-49$ \\
\hline & & 2002 & $47-52$ \\
\hline & & 2003 & $45-50$ \\
\hline & & 2004 & $42-47$ \\
\hline & & 2005 & $44-49$ \\
\hline & & 2006 & $40-45$ \\
\hline & & & $46-51$ \\
\hline
\end{tabular}

Table 3: Meteorological drought for Bankura station

\begin{tabular}{|l|l|l|l|}
\hline Year & Annual Rainfall & Deviation (\%) & Drought \\
\hline 2000 & 956.7 & -24.26 & Mild \\
\hline 2001 & 1328.7 & 5.19 & No \\
\hline 2002 & 1872.7 & 48.26 & No \\
\hline 2003 & 1493.1 & 18.21 & No \\
\hline 2004 & 1709.7 & 35.35 & No \\
\hline 2005 & 1437.8 & 13.82 & No \\
\hline 2006 & 1306.3 & 3.42 & No \\
\hline 2007 & 1845.9 & 46.14 & No \\
\hline
\end{tabular}

Mild drought- $13 \%$ and No drought $-87 \%$

Table 4: Meteorological drought for Canning station

\begin{tabular}{|l|l|l|l|}
\hline Year & Annual Rainfall & Deviation (\%) & Drought \\
\hline 1992 & 1751.3 & 0.66 & No \\
\hline 1993 & 1745.1 & 0.30 & No \\
\hline 1994 & 1510.8 & -13.17 & Mild \\
\hline 1995 & 2019.0 & 16.04 & No \\
\hline 1996 & 1862.2 & 7.03 & No \\
\hline 1997 & 1746.7 & 0.39 & No \\
\hline 1998 & 2020.1 & 16.11 & No \\
\hline 1999 & 2038.9 & 17.19 & No \\
\hline 2002 & 1907.1 & 9.61 & No \\
\hline 2003 & 2152.2 & 23.70 & No \\
\hline 2004 & 1745.3 & 0.31 & No \\
\hline 2005 & 2119.9 & 21.84 & No \\
\hline 2006 & 1966.9 & 13.05 & No \\
\hline
\end{tabular}




\section{Seasonal rainfall analysis:}

Bankura: The annual average rainfall at Bankura station was $1494 \mathrm{~mm}$. The rainfall amount during different season namely winter, summer, south-west and north east rainfall were respectively 2, 13, 77 and $8 \%$ of the total rainfall. The coefficient of variation of seasonal rainfall was highest (98\%) during winter season followed by North-East monsoon season (79\%). However, the coefficient of variation (CV) was moderate during south-west monsoon season and lowest (11\%) during summer season. (Table 5)

Canning station: The annual average rainfall for Canning station was $1891 \mathrm{~mm}$. The contribution of winter, summer, south-west, north-east monsoon was respectively 1, 12, 75 \& 12\%. During winter and north-east monsoon the CV values followed more less similar trend like Bankura station. However, reversed trend of CV was observed for summer and south-west monsoon season (Table 6).

Table 5: Seasonal rainfall analysis of Bankura station

\begin{tabular}{|l|l|l|l|l|l|}
\hline & Winter & Summer & South-West & North-East & Annual \\
\hline Mean & 32.1 & 193.9 & 1153.5 & 114.4 & 1493.9 \\
\hline SD & 31.6 & 22 & 291 & 90.1 & 309 \\
\hline CV & 98.4 & 11.3 & 25.2 & 78.7 & 20.7 \\
\hline
\end{tabular}

Table 6: Seasonal rainfall analysis of Canning station

\begin{tabular}{|l|l|l|l|l|l|}
\hline & Winter & Summer & South-West & North-East & Annual \\
\hline Mean & 23.7 & 219.8 & 1414.2 & 233.5 & 1891.2 \\
\hline SD & 22.2 & 79.2 & 156.2 & 159.7 & 184.8 \\
\hline CV & 93.6 & 36 & 11 & 68.4 & 9.8 \\
\hline
\end{tabular}

\section{Rainfall probability analysis (Two wet weeks):}

Bankura: Probability of two consecutive wet weeks with different level (10, 20, 30, 40, 50 and $60 \mathrm{~mm}$ ) of weekly total rainfall was estimated (Fig. 3). When only $10 \mathrm{~mm}$ is considered, more than $75 \%$ probability is assured at $21^{\text {st }}$ SMW, which continued upto $37^{\text {th }}$ SMW followed by gradual decrease. In case of $20 \mathrm{~mm}$ rainfall, $75 \%$ probability of two consecutive week starts at $24^{\text {th }}$ SMW and end at 30 SMW. For $30 \mathrm{~mm}$ weekly total rainfall the same confined between $24^{\text {th }}$ SMW and $28^{\text {th }}$ SMW. If we consider $50 \%$ probability of getting two consecutive wet weeks with $30 \mathrm{~mm}$ rainfall the span extended from $23^{\text {rd }}$ SMW to $30^{\text {th }}$ SMW. In case of $40 \mathrm{~mm}$ weekly total rainfall $75 \%$ probability of getting two consecutive wet weeks is only happened on $28^{\text {th }}$ SMW. But $50 \%$ probability of getting such wet weeks starts from $24^{\text {th }} \&$ ends at $29^{\text {th }}$ SMW. There is no chance of getting two wet weeks (50mm weekly total rainfall) with $75 \%$ probability level. At $24^{\text {th }} \& 25^{\text {th }}$ week there is a chance of getting 50mm rainfall with 63\% probability level (more than 50\%). There is a chance of getting two wet weeks (within $60 \mathrm{~mm}$ rainfall) with $50 \%$ probability level only on $25^{\text {th }}$ SMW.

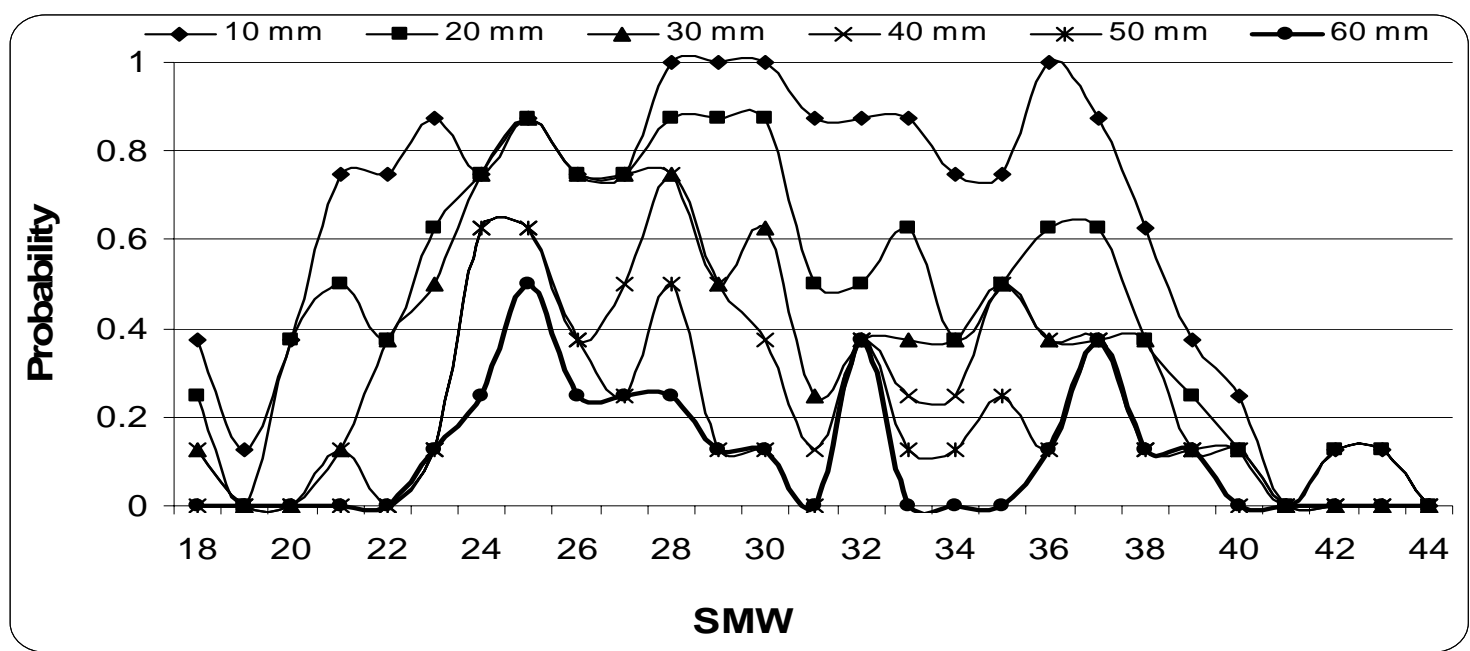

Fig. 3: Probability of getting consecutive two wet week for Bankura 
Canning: Probability of two consecutive wet weeks with different level (10, 20, 30, 40, 50 and $60 \mathrm{~mm}$ ) of weekly total rainfall was estimated (Fig 4). When only $10 \mathrm{~mm}$ is considered, more than $75 \%$ probability is assured at $25^{\text {th }}$ SMW, which continued upto $38^{\text {th }}$ SMW followed by gradual decrease. In case of $20 \mathrm{~mm}$ rainfall, $75 \%$ probability of two consecutive week starts at $28^{\text {th }}$ SMW and end at 32 SMW. For $30 \mathrm{~mm}$ weekly total rainfall the same confined between $28^{\text {th }}$ SMW and $32^{\text {nd }}$ SMW. If we consider $50 \%$ probability of getting two consecutive wet weeks with $30 \mathrm{~mm}$ rainfall the span extended from $28^{\text {th }}$ SMW to $36^{\text {th }}$ SMW. In case $40 \mathrm{~mm}$ weekly total rainfall $75 \%$ probability of getting two consecutive wet weeks is only happened on 30 and $31^{\text {st }}$ SMW. But $50 \%$ probability of getting such wet weeks starts from $25^{\text {th }} \&$ ends at $36^{\text {th }}$ SMW. There is only one (30 SMW) chance of getting two wet weeks (50mm weekly total rainfall) with $75 \%$ probability level. From $28^{\text {th }}$ to $32^{\text {nd }}$ SMW there is a chance of getting $50 \mathrm{~mm}$ rainfall with more than $50 \%$ probability level. There is a chance of getting two wet weeks (within 60mm rainfall) with 50\% probability level from 30-32 SMW. However there is no chance no chance at $75 \%$ probability level.

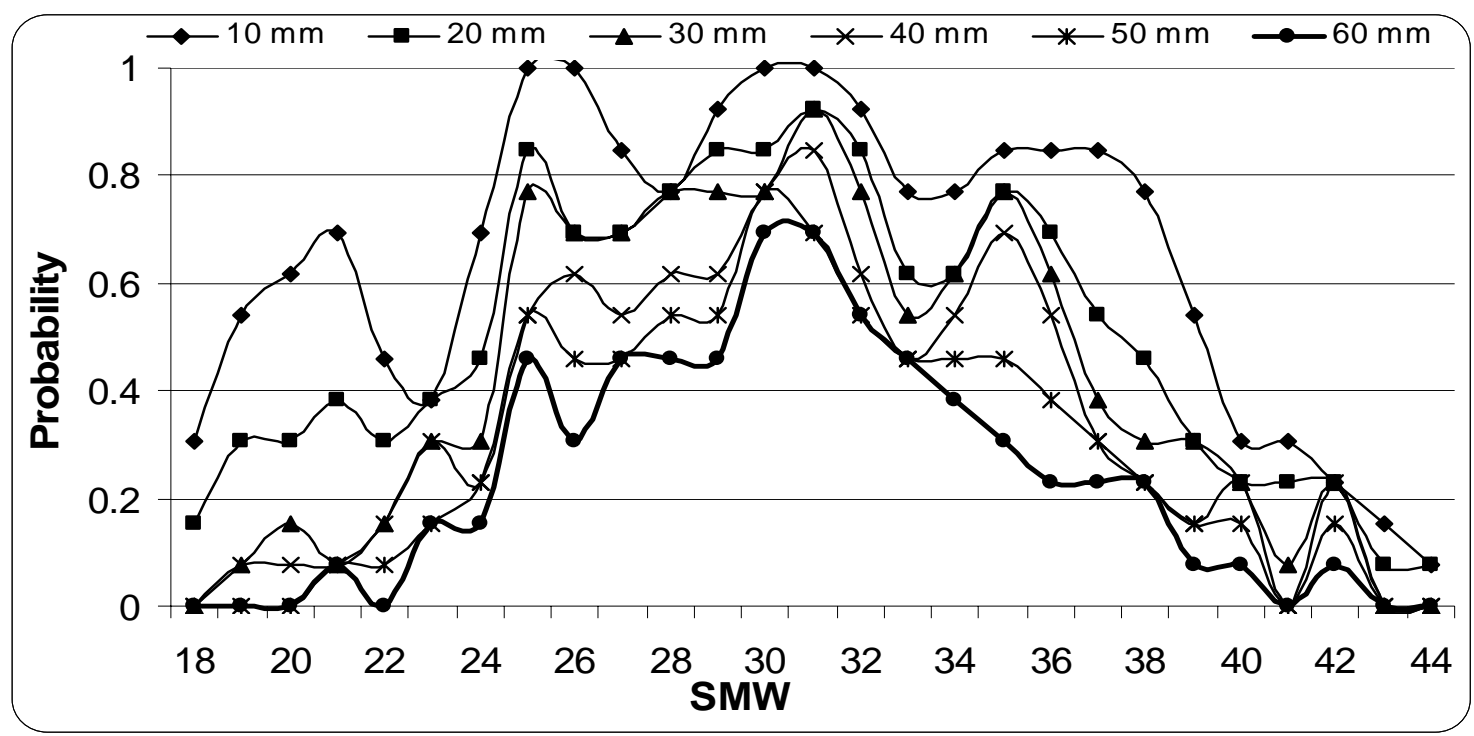

Fig. 4 Consecutive two wet week for Canning

Hence, it can be concluded that for both the station, no wide stretch of wet weeks (getting about 40 to $50 \mathrm{~mm}$ rainfall) was obtained. So, supplemented irrigation will be very much useful for these two zones under study.

\section{ACKNOWLEDGEMENT}

The weather data receipt from IMD is duly acknowledged.

\section{REFERENCES}

Bankura.org. Website accessed on 05.05.10.

Chakraborty, P.K. and Chakraborty, A.K. 1991. Assured rainfall in Nadia district and its effect on cropping pattern. Env. and Ecology. 9(1): 81-83.

Chakraborty, P.K., Huda, A.K.S., Chatterjee, B.N. and Khan, S.A. 1990. Rainfall and its impact on cropping pattern in Hoogli district of West Bengal. Indian J. of Agric. Sciences. 60(2): 101106.

Thom, H.C.S.,1966, 'Some methods of climatological analysis, WMO Tech. Note No. 81, pp. 20-22 